\title{
Low-density lipoprotein subclasses: mechanisms of formation and modulation
}

\author{
BY BRUCE A. GRIFFIN \\ Centre for Nutrition and Food Safety, School of Biological Sciences, University of Surrey, \\ Guildford GU2 $5 X H$
}

A predominance of small, dense LDL has been consistently associated with an increased relative risk of CHD and may be directly involved in the atherogenic process via a number of credible mechanisms (Austin, 1991; Griffin, 1995). Whilst plasma triacylglycerols (TAG) measured in the post-absorptive state have emerged in all studies as the major determinant of increased small, dense LDL, postprandial events may be paramount in influencing not only fasting TAG levels, but also the heterogeneity of TAG-rich lipoproteins (TGRL), and the lipolytic and lipid transfer reactions which modulate LDL subclasses.

Evidence in support of a link between postprandial lipaemia and fasting TAG status is based on the following. First, the duration of postprandial lipaemia overlaps significantly with feeding frequency, placing the majority of individuals in a postprandial state for up to $16 \mathrm{~h} / \mathrm{d}$ (Jenkins et al. 1989). Thus, differences in fasting TAG may simply reflect variable degrees of enhanced postprandial lipaemia. In addition, the delivery of exogenous TAG to the liver rather than the periphery in the form of chylomicron remnants may provide a stimulus for the production of VLDL. Second, significant increases in large, TAG-rich VLDL have been shown to occur in postprandial plasma (Karpe et al. 1993a,b). Finally, numerous studies have revealed positive relationships between fasting TAG levels and the extent of postprandial lipaemia in response to an oral fat load (Lewis et al. 1991; O'Meara et al. 1992). Taken together, these findings suggest that fasting TAG may reflect the cumulative outcome of repeated episodes of postprandial lipaemia which could fuel the mechanism for the remodelling of LDL subclasses, i.e. that of neutral-lipid exchange.

\section{CONVERGENT HISTORY OF LDL SUBCLASSES AND POSTPRANDIAL LIPAEMIA}

The roles of LDL heterogeneity and postprandial lipaemia in coronary disease have recently converged through their mutual relationship with insulin resistance. The concept of atherosclerosis as a postprandial phenomenon (Zilversmit, 1979) has been sustained by formulation of the TAG intolerance hypothesis (Meisenbock \& Patsch, 1992). This drew clinical attention to the power of postprandial lipaemia as a discriminator of coronary risk and showed how postprandial events may confer increased atherogenic potential on apolipoprotein (apo) B-containing remnants (Patsch et al. 1992), and more recently on LDL (Lechleitner et al. 1994).

Concurrent developments in the field of LDL subclasses included the first systematic description of LDL heterogeneity within and between individuals (Table 1; Krauss \& Burke, 1982), the demonstration of the clinical significance of small, dense LDL as a genetic marker of CHD risk (Austin \& Krauss, 1986; Austin et al. 1988), and the definition of an atherogenic lipoprotein phenotype (ALP; Austin et al. 1990), a collection of abnormalities in plasma lipoproteins that is intimately associated with insulin resistance and hyperinsulinaemia (Reaven et al. 1993). Whilst in retrospect it is apparent that LDL subclasses and postprandial lipaemia are common to patient groups with variable degrees of insulin resistance, few studies have been able to address the practical and technical 
Table 1. Classification of human plasma LDL subclasses

\begin{tabular}{|c|c|c|c|}
\hline LDL subclass & $\begin{array}{l}\text { Peak density interval } \\
(\mathrm{g} / \mathrm{ml})^{*}\end{array}$ & $\begin{array}{l}\text { Peak diameter } \\
(\mathrm{nm}) \dagger\end{array}$ & Features \\
\hline LDL-I & $1.025-1.034$ & $27 \cdot 5-26 \cdot 0$ & $\begin{array}{l}\text { Component of LDL subclass pattern 'A' } \\
\text { Inversely related to plasma TAG and CHD risk, } \\
\text { positively associated with } \mathrm{HDL}_{2} \\
\text { Raised levels in females may be receptor active via } \\
\text { apo } E \text { and apo B }\end{array}$ \\
\hline LDL-II & $1.034-1.044$ & $26 \cdot 4-25 \cdot 5$ & $\begin{array}{l}\text { Major component of LDL subclass pattern 'A' } \\
\text { Principal carrier of cholesteryl esters, most abundant } \\
\text { LDL subclass in normolipidaemic plasma and in } \\
\text { LDL receptor deficiency } \\
\text { Most receptor-active subclass via apo B-100 }\end{array}$ \\
\hline LDL-III & $1.044-1.060$ & $25 \cdot 5-24 \cdot 2$ & $\begin{array}{l}\text { Major component of LDL subclass pattern ' } B \text { ' } \\
\text { Positively associated with plasma TAG and CHD } \\
\text { risk } \\
\text { Predominates in insulin resistant states } \\
\text { Oxidatively labile and relatively receptor-inactive }\end{array}$ \\
\hline
\end{tabular}

TAG, triacylglycerol; apo, apolipoprotein.

* Density intervals determined by density-gradient centrifugation.

$\uparrow$ LDL particle size determined by gradient gel electrophoresis.

constraints involved in measuring both dyslipidaemic phenomena. An extensive study by Karpe et al. (1993b) showed small, dense LDL to be associated with the concentration of chylomicron remnants and VLDL in the postprandial phase. LDL size has also been shown to predict the magnitude and duration of postprandial lipaemia in controls, CHD and noninsulin-dependent diabetes mellitus (NIDDM; Nikkila et al. 1994; Tan, K. C. B. et al. 1995).

Although acute changes in LDL subclasses in response to postprandial lipaemia have been less evident, an increase in the proportion of the LDL subclass of intermediate density (LDL-II) at the expense of the smaller, denser LDL-III has been reported in normotriacylglycerolaemic NIDDM and controls postprandially (Attia et al. 1995). This finding may have significance in relation to the role of cholesteryl ester (CE) transfer protein (CETP) in normolipidaemic plasma and the accelerated transfer of CE from HDL into LDL-II, the most receptor-active LDL subclass (Nigon et al. 1991). Overall, the weight of evidence for a relationship between LDL subclasses and enhanced postprandial lipaemia is now such that many believe the latter should feature in the definition of an ALP. This idea gains further support from the process of neutral-lipid exchange which links LDL subclasses and TGRL, although what exactly should be measured as a reliable index of postprandial lipaemia is complicated by difficulty in the characterization of TGRL.

\section{NEUTRAL-LIPID EXCHANGE}

First proposed by Nichols \& Smith (1965), neutral-lipid exchange traditionally describes the process by which $\mathrm{CE}$ are transferred from CE-rich lipoproteins in equimolar exchange for TAG from TGRL. This transfer is mediated through the joint action of lipid transfer proteins, most notably CETP, and endothelial lipases, and is largely responsible for the remodelling of LDL and HDL subclasses in plasma. It is important to appreciate that the absolute and relative concentrations of the substrate lipoproteins, particularly TGRL, are critical in modulating the direction of lipid transfer between lipoproteins. 


\section{PLASMA TRIACYLGLYCEROLS AND LDL SUBCLASSES}

Large-scale lipid screening programmes have shown that as plasma TAG increases up to a value of $2 \mathrm{mmol} / \mathrm{l}$, LDL mass increases in parallel but then falls away sharply above this value. One plausible explanation for this relationship, based on the kinetics of tracerlabelled LDL in vivo, employs the concept of metabolic heterogeneity (Caslake et al. 1992). This postulates the existence of two distinct pools of LDL with 'rapid' and 'slow' rates of removal from plasma. The structural counterparts of these metabolic pools are LDL subclass patterns ' $A$ ' and ' $B$ ' which, in theory, correspond to the rapidly- and slowlyremoved pools respectively. Thus, the increase in LDL which accompanies the rise in plasma TAG is explained by a shift in the distribution of LDL from a rapidly-removed pool to a slowly-removed pool, resulting in a decrease in LDL catabolism. In this model, the rate at which LDL is removed is governed chiefly by a decrease in the affinity of LDL as a ligand for its receptor, as LDL subclasses redistribute from predominantly large LDL (pattern A) to small, dense LDL (pattern B).

Closer examination of the relationship between LDL subclasses and TAG in a casecontrol study revealed that the increase in $\mathrm{LDL}$ up to a TAG value of $1.5 \mathrm{mmol} / \mathrm{l}$ was due to an increase in the LDL-II subclass, with minor contributions from large LDL-I and small, dense LDL-III (Griffin et al. 1994). Above $1.5 \mathrm{mmol} / \mathrm{l}$, small, dense LDL-III was shown to increase significantly (Fig. 1(a)), whilst the concentration of the larger LDL-II and LDL-I fell, resulting in a levelling-off of total LDL mass as seen previously. This apparent threshold level of plasma TAG also coincided with a plasma concentration of small, dense LDL-III (1000 mg/l) which was critical in discriminating between groups with and without coronary artery disease (Fig. 1(b)). Extension of this work to larger groups of normal males and females confirmed these relationships between LDL subclasses and TAG in males but not in females within whom the mass of LDL-II continued to rise above the TAG threshold (Tan, C. E. et al. 1995). Females also showed a significantly reduced increment in small, dense LDL-III above $1.5 \mathrm{mmol} / \mathrm{l}$ as compared with males (17\% females $v .47 \%$ males with LDL-III $>1000 \mathrm{mg} / \mathrm{l})$. This difference was ascribed to lower levels of hepatic lipase (EC 3.1.1.3) activity in females. This enzyme has a pivotal role in the remodelling of large LDL into small LDL through its action on LDL-TAG. Hence, LDL subclasses were shown to redistribute at about a TAG threshold of $1.5 \mathrm{mmol} / \mathrm{l}$, a finding concordant with the influence of TAG-lowering drugs (Superko \& Krauss, 1992; Caslake et al. 1993). This relatively low TAG value has been ascribed clinical significance in NIDDM (Lahdenpera et al. 1996) and in the expression of small, dense LDL in an ALP (Austin et al. 1990), suggesting that current action limits for intervention may be too high. In quantitative terms, this threshold will almost certainly be breached by postprandial lipaemia in the majority of individuals throughout the day, though recent studies indicate that the quality of postprandial TGRL may be of greater importance in the modulation of LDL subclasses.

\section{TRIACYLGLYCEROL-RICH LIPOPROTEINS}

Postprandial increases in TAG are associated mainly with chylomicrons and their remnants, which carry considerably more TAG per particle than VLDL. Nevertheless, $80 \%$ of the increase in total apo $\mathrm{B}$, and thus particle number, has been shown to be associated with VLDL (Schneeman et al. 1992). This postprandial VLDL is largely in the

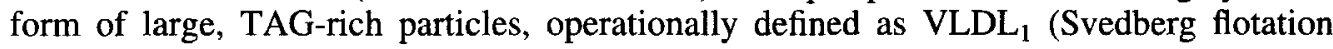
units $\left(S_{f}\right) 60-400$ ). In common with chylomicron remnants, VLDL ${ }_{1}$ is removed directly from the plasma by receptors which are specific for apo $\mathrm{E}$, as distinct from smaller VLDL 2 $\left(S_{\mathrm{f}} 20-60\right)$, most of which is catabolized to LDL (Shepherd \& Packard, 1987). Elevated 
(a)

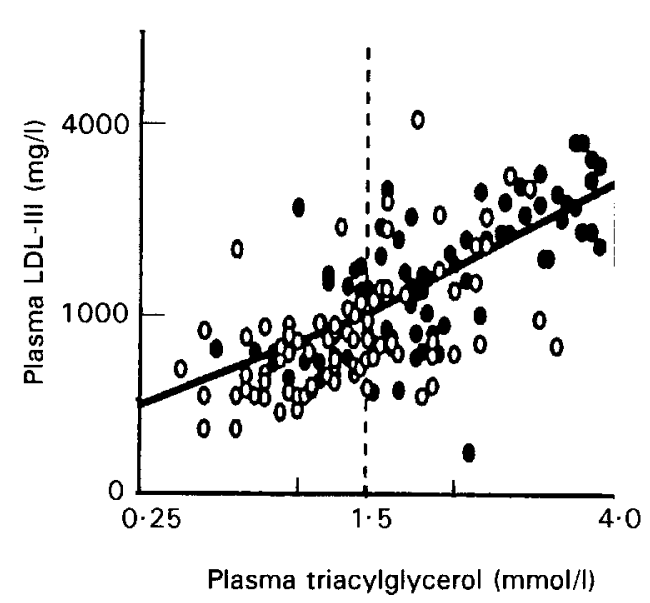

(b)

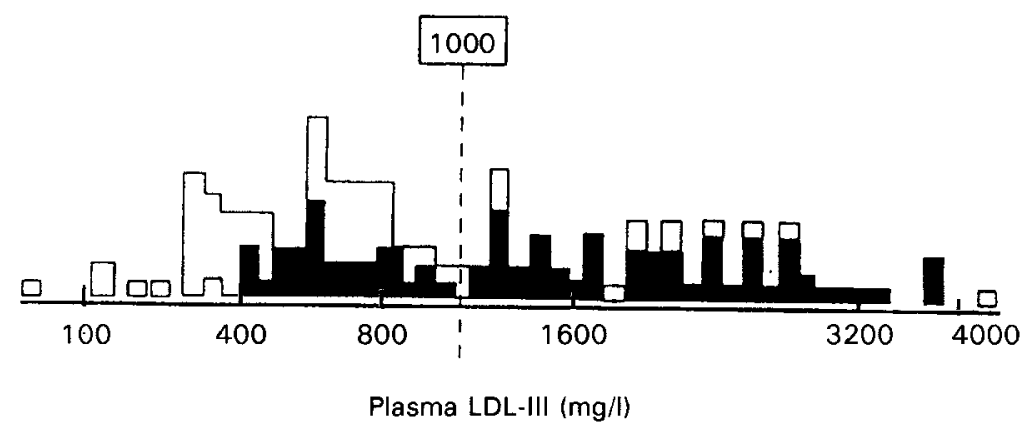

Fig. 1. (a) Association of small, dense LDL with plasma triacylglycerol in male subjects with (O) and without $(O)$ CHD. The concentration of small, dense LDL-III correlates with plasma triacylglycerol $(r 0.54, P<0.001)$ above a triacylglycerol threshold value of $1.5 \mathrm{mmol} /$. This triacylglycerol value corresponds to an LDL-III concentration of $1000 \mathrm{mg} / \mathrm{l}$, which is significant as a cut-off point between CHD ( $\square$ ) and non-CHD ( $\square$ ) groups in the bimodal frequency distribution of LDL-III (b). Based on data from Griffin et al. (1994).

levels of plasma VLDL 1 in insulin-resistant states such as obesity and NIDDM (James \& Pometta, 1991; Fisher et al. 1993) are believed to characterize the overproduction of endogenous TAG by the liver, which can be normalized by insulin therapy (Taskinen et al. 1990) and hyperinsulinaemic clamps (Lewis et al. 1993). Large VLDL $_{1}$ is also a major contributor to increases in fasting TAG level above $1.5 \mathrm{mmol} / \mathrm{l}$ in normal, healthy subjects (Tan, C. E. et al. 1995) and acts as an excellent acceptor of CE from LDL in vitro

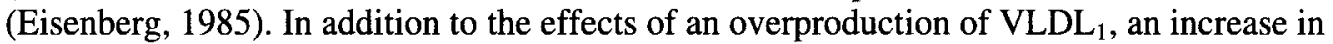
its residence time in plasma, which may occur as a result of competitive interactions between chylomicron remnants and $\mathrm{VLDL}_{1}$ for LPL (Bjorkegren et al. 1996), will significantly enhance its role in neutral-lipid exchange. Further evidence to link defects in the lipolysis or receptor-mediated removal of $\mathrm{VLDL}_{1}$ with small, dense LDL is provided 
by the accumulation of apo E-poor $\mathrm{VLDL}_{1}$ in hypertriacylglycerolaemia (Evans et al. 1989) and a strong inverse relationship between the percentage of small, dense LDL-III and plasma apo E (Attia et al. 1995), the latter of which will largely reflect VLDL-apo E. Thus, as a reservoir of TAG for neutral-lipid exchange and potential progenitor of small, dense $\mathrm{LDL}$, the level of $\mathrm{VLDL}_{1}$ in post-absorptive plasma is perhaps the most appropriate marker of postprandial lipaemia in relation to LDL subclasses. However, this would seem to conflict with the finding of a predominance of small, CE-rich $\mathrm{VLDL}_{2}$ in an ALP (Bavenholm et al. 1995). This apparent discrepancy between studies may reflect a difference in emphasis on either the concentration of apo $\mathrm{B}$ as a marker of an increased number of $\mathrm{VLDL}_{2}$ particles or an increase in total $\mathrm{VLDL}_{1}$ mass as a result of its TAG content.

\section{LIPOPROTEIN AND HEPATIC LIPASES}

Lipoprotein lipase (EC 3.1.1.34; LPL) has a rate-limiting role in regulating the quality and quantity of circulating TGRL available for neutral-lipid exchange reactions, especially during the postprandial phase. However, this is not always reflected in statistical relationships with LDL subclasses, probably because their relationship with LPL is indirectly mediated through TGRL. Subnormal LPL activity, measured as post-heparin lipolytic activity, is a well-recognized feature of NIDDM (Taskinen, 1995) and has been inversely correlated with LDL particle size in this group (Lahdenpera et al. 1996). Conversely, LPL is positively related to the concentration of light LDL-cholesterol (LDLI + II; Karpe et al. 1993b). This would suggest that large LDL is a marker of efficient lipolysis of TAG in LPL-rich peripheral tissues such as skeletal muscle and adipose tissue, which, in effect, will lower fasting and postprandial levels of TGRL and limit the net mass transfer of TAG into LDL via neutral-lipid exchange.

In contrast to LPL, hepatic lipase is involved in the remodelling of smaller CE-rich lipoproteins (IDL, LDL, HDL) and, as a direct consequence, is a frequent component of multivariate models to explain variation in LDL subclasses, being inversely related to LDL size through its hydrolytic action on LDL-TAG (Watson et al. 1994; Zambon et al. 1994; Tan, C. E. et al. 1995). Further evidence for this role of hepatic lipase comes from enzyme inhibition studies (Goldberg et al. 1982) and human hepatic lipase deficiency (Auwerx et al. 1989), both of which result in an accumulation of large, buoyant LDL (LDL-I). Hence, the actions of LPL and hepatic lipase have opposing influences on neutral-lipid exchange. Impaired LPL activity, particularly in adipose tissue during the postprandial phase, will effectively increase the residence time of large TAG-rich VLDL which in turn will promote the acquisition of TAG by LDL through neutral-lipid exchange. Once enriched with TAG, LDL becomes a favourable substrate for hepatic lipase, the action of which reduces its particle size. In this way, a deficiency of LPL and raised hepatic lipase activity can work together to promote the formation of small, dense LDL. LPL is an insulinsensitive enzyme which shows tissue-specific responsiveness to insulin in muscle and adipose tissue in post-absorptive and postprandial phases respectively (Frayn, 1993). Indeed, many of the environmental factors which modulate LDL subclasses, such as dietary fatty acids and exercise, probably do so by inducing the action of LPL through mechanisms of increased insulin sensitivity. On the other hand, hepatic lipase is largely regulated by the balance of androgens and oestrogens which are reported to selectively stimulate and suppress the activity of this enzyme respectively (Kissebah \& Schectman, 1987). Thus, a reduction in the activity ratio LPL: hepatic lipase in response to the development of insulin resistance in males and postmenopausal females should have predictably adverse effects on LDL subclasses. 


\section{LIPID TRANSFER REACTIONS: CHOLESTERYL ESTER TRANSFER PROTEINS}

The influence of CETP on the remodelling of LDL subclasses, if viewed in the context of reverse cholesterol transport, can be regarded as an essential and even beneficial process, whereas its involvement in the generation of small, dense LDL is clearly unfavourable. Whilst the changing role of LDL as an acceptor or donor of CE in these two different situations may be critical in determining the subsequent fate of $\mathrm{CE}$, the absolute and relative concentration of TGRL will ultimately dictate the direction of transfer of $\mathrm{CE}$ between lipoproteins.

In general, the transfer activity of CETP in plasma, as measured in vitro by a range of lipid transfer and mass assays, shows no relationship with plasma LDL subclasses. Nonetheless, there is a considerable body of evidence to implicate CETP in the remodelling of LDL subclasses and channelling of CE from HDL and large and small LDL into receptor-active LDL-II. The characterization of LDL subclasses in human CETP deficiency and the effects of alcohol provide some of the best evidence to implicate CETP in the modulation of LDL subclasses in vivo. Individuals with a complete deficiency of CETP in plasma present with an abnormal distribution of LDL subclasses consisting of large and small LDL and a relative lack of the major intermediate LDL-II subclass as compared with controls (Sakai et al. 1991). This pattern of LDL subclasses has also been found in heavy drinkers and is attributed to a marked inhibition of CETP activity by alcohol (Hirano et al. 1992). Most importantly, acute abstention from alcohol results in a dramatic return of CETP activity and normalization of the LDL subclass profile, suggesting that CETP shuttles CE from large LDL-I and small LDL-III into the intermediate LDL-II (Figs. 2(a and $b)$ ).

Further evidence for the role of CETP in remodelling LDL subclasses has been obtained from in vitro systems. These have shown that the induction of shifts in LDL subclasses requires a source of TAG-rich substrate and the joint actions of a lipase and CETP (Lagrost et al. 1994), as would be naturally present in vivo. More recent studies indicate that the transfer of CE can occur independently of TAG and that the non-esterified fatty acids can modulate neutral-lipid transfer in normolipidaemic plasma (Lagrost et al. 1995). If substantiated, this finding would have major implications for the role of dietary fatty acids in modulating reverse cholesterol transport. The transfer activity of plasma CETP, as measured in vitro using exogenous donor (HDL) and acceptor lipoproteins (VLDL + LDL), correlates with the mass of CETP but takes no consideration of the physiological ratios of substrate lipoproteins present in vivo. An assay system designed specifically to address this issue showed a heterogeneous pattern of $C E$ transfer between HDL and LDL subclasses in vitro which is consistent with the defects produced by CETP deficiency and alcohol (Guerin et al. 1994). Although the practical details of the assay are beyond the scope of the present review, the method revealed VLDL to be qualitatively superior to LDL as an acceptor of CE from HDL. However, in quantitative terms, LDL-II was the most active acceptor of $\mathrm{CE}$ from HDL in normolipidaemic plasma. As might be expected, small, dense LDL-III was a poor acceptor of CE from HDL. The majority of situations in which an increase in CETP activity, mass and even mRNA have been reported are associated with abnormal distributions of TGRL, LDL and HDL, as for example in NIDDM, and hypertriacylglycerolaemia (Tall, 1993). Under these circumstances, variations in CETP may well be secondary to the changes in TGRL, the latter of which are likely to be a rate-limiting factor in the transfer of $\mathrm{CE}$ and modulation of LDL subclasses. Thus, correction of the underlying dyslipidaemia should be sufficient to correct the elevations in CETP-mediated lipid transfers. 
(a)

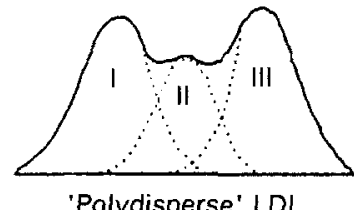

'Polydisperse' LDL

CETP deficiency

Alcohol (8-15 units/d)
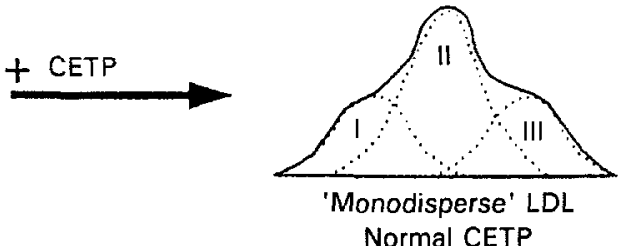

Alcohol withdrawal

(b)

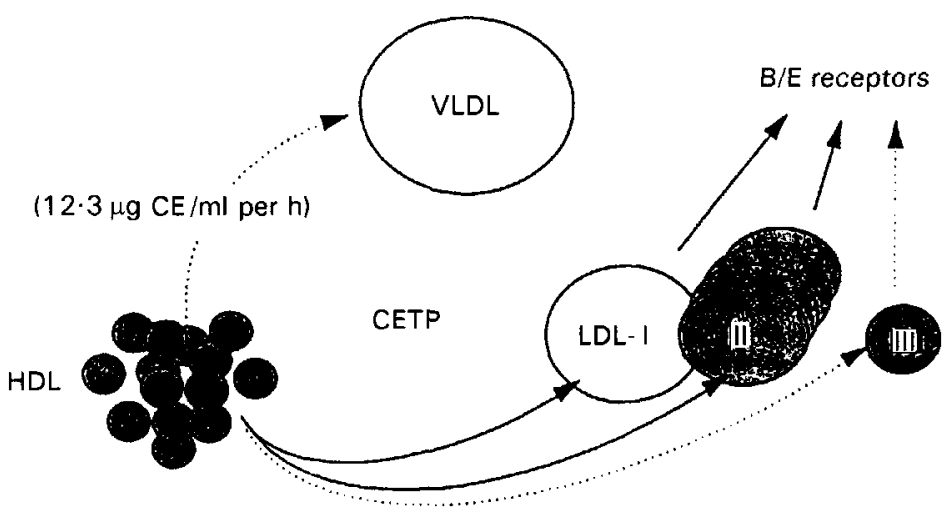

(33.5 $\mu \mathrm{g} \mathrm{CE} / \mathrm{ml}$ per h)

Fig. 2. (a) Effects of cholesteryl ester transfer protein (CETP) deficiency and chronic alcohol consumption on LDL subclass profile which shows a lack of intermediate LDL-II. This is corrected in the presence of CETP activity and after alcohol withdrawal. (Based on data from Sakai et al. 1991 and Hirano et al. 1992.) (b) Model of neutral-lipid exchange showing the CETP-mediated net mass transfer of cholesteryl esters (CE) into receptor-active LDL species LDL-I and LDL-II. B/E, apolipoprotein B and E. (Model based on in vitro data of Guerin et al. 1994.)

\section{POSTPRANDIAL CHOLESTERYL ESTER TRANSFER PROTEIN ACTIVITY}

A pronounced stimulation of $C E$ transfer has been reported to occur during postprandial lipaemia, through an increase in TGRL and the activity of CETP (Tall et al. 1986). There are now data to suggest that the stimulation of $\mathrm{CE}$ transfer by lipolysis as a result of the accumulation of fatty acids on the surface of TGRL may occur in vivo (Tall, 1993). Whatever the mechanism, LDL would be expected to donate CE to and receive TAG from TGRL in the postprandial phase, limiting its function in the reverse transport of CE to the liver and favouring the generation of small, dense LDL. Compositional modification of postprandial LDL consistent with the net exchange of TAG into LDL has been shown previously and implicated in the increased oxidative susceptibility and atherogenicity of postprandial LDL (Lechleitner et al. 1994).

\section{APOLIPOPROTEIN E}

The existence of apo $E$ in LDL is often disputed because of the contamination of LDL preparations with IDL and even HDL, and also due to dissociation of this apolipoprotein from LDL in the ultracentrifuge. Nevertheless, the removal of large LDL species in the 
condition familial defective binding apo $B$ in which the receptor-binding function of LDL is defective, is thought to account for the relatively mild hypercholesterolaemia, and accumulation of small dense LDL in this group (Marz et al. 1993). Apo E in large LDL may also provide an explanation for the cholesterol-lowering effects of low-fat diets (Dreon et al. 1995). In this case, dietary responsiveness was graded according to apo $\mathrm{E}$ phenotype in a decreasing order of dietary responsiveness from apo $E_{4}$, to apo $E_{3}$ to apo $E_{2}$. An alternative explanation for this effect could be the impact of delayed clearance of TGRL remnants in apo $E_{4}$ subjects, as reported recently by Bergeron \& Havel (1996), resulting in a compensatory increase in the activity of LDL receptors.

\section{CONCLUSION}

Repeated episodes of enhanced postprandial lipaemia may underlie the relationship between fasting plasma TAG and the predominance of small, dense LDL, through a mechanism of increased neutral-lipid exchange. Impaired LPL activity, most notably in adipose tissue, may be critical in promoting an increase in plasma TAG, largely in the form of $\mathrm{VLDL}_{1}$, to above a threshold value of about $1.5 \mathrm{mmol} / \mathrm{l}$. This fuels the CETP-mediated net transfer of TAG into LDL which is then rapidly hydrolysed by the action of hepatic lipase, reducing LDL particle size. The onset of insulin resistance in males, and in postmenopausal females, may be of paramount importance in lowering the activity ratio of these lipases, thus favouring the formation of potentially atherogenic, small, dense LDL.

\section{REFERENCES}

Attia, N., Durlach, V., Paul, J. P., Soni, T., Betoulle, D. \& Girard-Globa, A. (1995). Modulation of low density lipoprotein subclasses by alimentary lipemia in control and normotriglyceridemia non-insulin dependent diabetic subjects. Atherosclerosis 113, 197-209.

Austin, M. A. (1991). Plasma triglyceride and coronary heart disease. Arteriosclerosis \& Thrombosis 11, 2-14.

Austin, M. A., Breslow, J. L., Hennekens, C. H., Burling, J. E., Willett, W. C. \& Krauss, R. M. (1988). Low density lipoprotein subclass patterns and risk of myocardial infarction. Journal of the American Medical Association 260, 1917-1921.

Austin, M. A., King, M. C., Vranizan, K. M. \& Krauss, R. M. (1990). Atherogenic lipoprotein phenotype. A proposed genetic marker for coronary heart disease. Arteriosclerosis \& Thrombosis 82, 495-506.

Austin, M. \& Krauss, R. M. (1986). Genetic control of low density lipoprotein subclasses, Lancet ii, 592-594.

Auwerx, J. H., Marzetta, C. A., Hokanson, J. E. \& Brunzell, J. D. (1989). Large buoyant LDL-like particles in hepatic lipase deficiency. Arteriosclerosis 9, 319-325.

Bavenholm, P., Karpe, F., Proudler, A., Tornvall, P., Crook, D. \& Hamsten, A. (1995). Association of insulin and insulin propeptides with an atherogenic lipoprotein phenotype. Metabolism 44, 1481-1488.

Bergeron, N. \& Havel, R. J. (1996). Prolonged postprandial responses of lipids and apolipoproteins in triglyceride-rich lipoproteins of individuals expressing an apolipoprotein 84 allele. Journal of Clinical Investigation 97, 65-72.

Bjorkegren, J., Packard, C. J., Hamsten, A., Bedford, D., Caslake, M. J., Foster, L., Shepherd, J., Stewart, P. \& Karpe, F. (1996). Accumulation of large very low density lipoprotein in plasma during intravenous infusion of a chylomicron-like triglyceride emulsion reflects competition for a common lipolytic pathway. Journal of Lipid Research 37, 76-86.

Caslake, M. J., Packard, C. J., Gaw, A., Murray, E., Griffin, B. A., Vallance, B. D. \& Shepherd, J. (1993). Fenofibrate and LDL heterogeneity in hypercholesterolaemia. Arteriosclerosis \& Thrombosis 13, 702-711.

Caslake, M. J., Packard, C. J., Series, J. J., Yip, B., Dagen, M. M. \& Shepherd, J. (1992). Plasma triglyceride and low density lipoprotein metabolism. European Journal of Clinical Investigation 22, 96-104.

Dreon, D. M., Fernstrom, H. A., Miller, B. \& Krauss, R. M. (1995). Apolipoprotein E isoform phenotype and LDL subclass response to a reduced fat diet. Arteriosclerosis \& Thrombosis 15, 105-111.

Eisenberg, S. (1985). Preferential enrichment of large-sized very low density lipoprotein population with transferred cholesteryl esters. Journal of Lipid Research 26, 487-493.

Evans, A. J., Huff, M. W. \& Wolfe, B. M. (1989). Accumulation of an apo E-poor subfraction of very low density lipoprotein I hypertriglyceridemic men. Journal of Lipid Research 30, 1691-1701. 
Frayn, K. N. (1993). Insulin resistance and lipid metabolism. Current Opinion in Lipidology 4, $197-204$.

Fisher, R. M., Coppack, S. W., Gibbons, G. F. \& Frayn, K. N. (1993). Post-prandial VLDL subfraction metabolism in normal and obese subjects. International Journal of Obesity 17, 263-269.

Griffin, B. A. (1995). Low density lipoprotein heterogeneity. Ballière's Clinical Endocrinology and Metabolism 9, 687-703.

Griffin, B. A., Freeman, D. J., Tait, G. W., Thomson, J., Caslake, M. M., Packard, C. J. \& Shepherd, J. (1994). Role of plasma triglyceride in the regulation of plasma low density lipoprotein (LDL) subfractions: relative contribution of small, dense LDL to coronary heart disease risk. Atherosclerosis 106, 241-253.

Goldberg, I. J., Ngoc-Anh Le, Paterniti, J. R. \& Ginsberg, H. N. (1982). Lipoprotein metabolism during acute inhibition of hepatic triglyceride lipase in the cymologous monkey. Journal of Clinical Investigation $\mathbf{7 0}$, $1184-1192$.

Guerin, M., Dolphin, P. J. \& Chapman, M. J. (1994). A new in vitro method for the simultaneous evaluation of cholesteryl ester exchange and mass transfer between HDL and apo B-containing lipoprotein subspecies. Identification of preferential cholesteryl ester acceptors in human plasma. Arteriosclerosis \& Thrombosis 14, 199-206.

Hirano, K., Matsuzawa, Y., Sakai, N., Hiraoka, H., Nozaki, S., Funahashi, T., Yamashita, S., Kubo, M. \& Tarui, S. (1992). Polydisperse low-density lipoproteins in hyperalphalipoproteinemic chronic alchohol drinkers in association with marked reduction of cholesteryl ester transfer protein activity. Metabolism 41, 1313-1318.

James, R. W. \& Pometta, D. (1991). The distribution profiles of very low density and low density lipoproteins in poorly-controlled male, Type 2 (non-insulin dependent) diabetic patients. Diabetologia 34, 246-252.

Jenkins, D. J. A., Wolever, T. M. S., Vuksan, V., Brighenti, F., Cunnane, S. C., Rao, A. V., Jenkins, A. L., Buckley, G., Patten, R., Singer, W., Corey, P. \& Josse, R. G. (1989). Nibbling versus gorging: metabolic advantages of increased meal frequency. New England Journal of Medicine 321, 929-934.

Karpe, F., Steiner, G., Olivecrona, T., Carlson, L. A. \& Hamsten, A. (1993a). Metabolism of triglyceride-rich lipoproteins during alimentary lipaemia. Joumal of Clinical Investigation 91, 748-758.

Karpe, F., Tornvall, P., Olivecrona, T., Steiner, G., Carlson, L. A. \& Hamsten, A. (1993b). Composition of human low density lipoprotein: Effects of postprandial triglyceride-rich lipoproteins, lipoprotein lipase, hepatic lipase and cholesteryl ester transfer protein. Atherosclerosis 98, 33-49.

Kissebah, A. H. \& Schectman, G. (1987). Hormones and lipoprotein metabolism. Ballière's Clinical Endocrinology and Metabolism 1, 699-725.

Krauss, R. M. \& Burke, D. J. (1982). Identification of multiple subclasses of plasma low density lipoproteins in humans. Journal of Lipid Research 23, 97-104.

Lagrost, L., Florentin, E., Guyard-Dangremont, V., Athias, A., Gandjini, H., Lallemant, C. \& Gambert, P. (1995). Evidence for nonesterified fatty acids as modulators of neutral lipid transfers in normolipidemic plasma. Arteriosclerosis, Thrombosis and Vascular Biology 15, 1388-1396.

Lagrost, L., Gambert, P. \& Lallemant, C. (1994). Combined effects of lipid transfers and lipolysis on gradient gel patterns of human plasma LDL. Arteriosclerosis \& Thrombosis 14, 1327-1336.

Lahdenpera, S., Syvanne, M., Kahri, J. \& Taskinen, M. R. (1996). Regulation of low-density lipoprotein particle size distribution in NIDDM and coronary disease: importance of serum triglycerides. Diabetologia 39, 453461.

Lechleitner, M., Hoppichler, F., Foger, B. \& Patsch, J. R. (1994). Low-density lipoproteins of the postprandial state induce cellular cholesteryl ester accumulation in macrophages. Arteriosclerosis \& Thrombosis 14, 1799 1807

Lewis, B. F., Uffelman, K. D., Szeto, L. W. \& Steiner, G. (1993). Effects of acute hyperinsulinaemia on VLDL triglyceride and VLDL apo B production in normal weight and obese individuals. Diabetes 42, 833-842.

Lewis, G. F., O'Meara, N. M., Soltys, P. A. \& Blackman, J. D. (1991). Fasting hypertriglyceridemia in noninsulin dependent diabetes mellitus is an important predictor of postprandial lipid and lipoprotein abnormalities. Journal of Clinical Enocrinology and Metabolism 72, 934-944.

Marz, W., Baumstark, M. W., Scarnagi, H., Ruzick, V., Buxbaum, S., Herwig, J., Pohl, T., Russ, A., Schaff, L., Berg, A., Bohles, H.-J., Usadel, K. H. \& Grob, W. (1993). Accumulation of small dense low density lipoproteins (LDL) in a homozygous patient with familial defective apolipoprotein B-100. Results from heterogenous interaction of LDL subfractions with the LDL receptor. Journal of Clinical Investigation 92 , 2922-2933.

Meisenbock, G. \& Patsch, J. R. (1992). Postprandial hyperlipidemia: the search for the atherogenic lipoprotein. Current Opinion in Lipidology 3, 196-201.

Nichols, A. V. \& Smith, L. (1965). Effect of very low density lipoproteins on lipid transfer in incubated serum. Journal of Clinical Investigation 6, 206-210.

Nigon, F., Lesnik, P., Rouis, M. \& Chapman, M. J. (1991). Discrete subspecies of human low density lipoproteins are heterogeneous in their interaction with the cellular LDL receptor. Journal of Lipid Research 32, 1741-1753.

Nikkila, M., Solakivi, T., Lehtimaki, T., Koivula, T., Kaippala, P. \& Astrm, B. (1994). Postprandial plasma lipoprotein changes in relation to apolipoprotein $\mathrm{E}$ phenotypes and low density lipoprotein size in men with and without coronary artery disease. Atherosclerosis 106, 149-157. 
O'Meara, N. M., Lewis, G. F., Cabana, V. G., Iverius, P. H., Getz, G. S. \& Polonsky, K. S. (1992). Role of basal triglyceride and high density lipoprotein in determination of postprandial lipid and lipoprotein responses. Journal of Clinical Endocrinology and Metabolism 75, 465-471.

Patsch, J. R., Meisenbock, G., Hopferwieser, T., Muhlberger, V., Knapp, E., Dunn, J. K., Gotto, A. M. \& Patsch, W. (1992). Relation of triglyceride metabolism and coronary artery disease. Studies in the postprandial state. Arteriosclerosis \& Thrombosis 12, 1336-1345.

Reaven, G. M., Chen, Y. D. I., Jeppesen, J., Maheux, P. \& Krauss, R. M. (1993). Insulin resistance and hyperinsulinaemia in individuals with small, dense low density lipoprotein particles. Journal of Clinical Investigation 92, 141-146.

Sakai, N., Matsuzawa, Y., Hirano, K., Yamashita, S., Nozaki, S., Ueyama, Y., Kubo, M. \& Tarui, S. (1991). Detection of two species of low density lipoprotein particles in cholesteryl ester transfer protein deficiency. Arteriosclerosis \& Thrombosis 11, 71-79.

Schneeman, B. O., Kotite, L., Todd, K. M. \& Havel, R. J. (1992). Relationships between the responses of triglyceride-rich lipoproteins in blood plasma containing apolipoproteins B-48 and B-100 to a fat-containing meal in normolipidemic humans. Proceedings of the National Academy of Sciences USA 90, 2069-2073.

Shepherd, J. \& Packard, C. J. (1987). Metabolic heterogeneity in very low density lipoproteins. American Heart Journal 113, 503-508.

Superko, H. R. \& Krauss, R. M. (1992). Differential effects on nicotinic acid in subjects with different LDL subclass patterns. Atherosclerosis $95,69-76$.

Tall, A., Sammett, D. \& Granot, E. (1986). Mechanisms of enhanced cholesteryl ester transfer from high density lipoproteins to apolipoprotein B-containing lipoproteins during alimentary lipemia. Journal of Clinical Investigation 77, 1163-1172.

Tall, A. R. (1993). Plasma cholesteryl ester transfer protein. Journal of Lipid Research 34, 1255-1274.

Tan, C. E., Forster, L., Caslake, M. J., Bedford, D., Watson, T. D. G., McConnell, M., Packard, J. \& Shepherd, J. (1995). Relations between plasma lipids and postheparin plasma lipases and VLDL and LDL subfraction patterns in normolipemic men and women. Arteriosclerosis, Thrombosis and Vascular Biology 15, 18391848.

Tan, K. C. B., Cooper, M. B., Ling, K. L. E., Griffin, B. A., Freeman, D. J., Packard, C. J., Shepherd, J., Hales, C. N. \& Betteridge, D. J. (1995). Fasting and postprandial determinants for the occurrence of small, dense LDL species in non-insulin dependent diabetic patients with and without hypertriglyceridaemia: the involvement of insulin, insulin precursor species and insulin resistance. Atherosclerosis 113, 273-287.

Taskinen, M.-R. (1995). Insulin resistance and lipoprotein metabolism. Current Opinion in Lipidology 6, 153160.

Taskinen, M.-R., Packard, C. I. \& Shepherd, J. (1990). Effect of insulin therapy on metabolic fate of apolipoprotein B-containing lipoproteins in NIDDM. Diabetes 39, 1017-1027.

Watson, T. D. G., Caslake, M. J., Freeman, D. J., Griffin, B. A., Hinnie, J., Packard, C. J. \& Shepherd, J. (1994). Determinants of LDL subfraction distribution and concentrations in young normolipidaemic subjects. Arteriosclerosis \& Thrombosis 14, 902-910.

Zambon, A., Austin, M. A., Brown, B. G., Hokanson, J. E. \& Brunzell, J. D. (1993). Effect of hepatic lipase on LDL in normal men and those with coronary heart disease. Arteriosclerosis \& Thrombosis 13, 147-153.

Zilversmit, D. B. (1979). Atherogenesis: a postprandial phenomenon. Circulation 60, 473-485. 